1

\title{
Spatial and temporal patterns of mass bleaching of corals in the Anthropocene
}

\section{The window for safeguarding the world's coral reefs from anthropogenic climate change is rapidly closing}

Terry P. Hughes ${ }^{1}$, Kristen D. Anderson ${ }^{1}$, Sean R. Connolly ${ }^{1,2}$, Scott F. Heron ${ }^{3,4}$, James T. Kerry $^{1}$, Janice M. Lough ${ }^{1,5}$, Andrew H. Baird ${ }^{1}$, Julia K. Baum ${ }^{6}$, Michael L. Berumen ${ }^{7}$ Tom C. Bridge ${ }^{1,8}$, Danielle C. Claar ${ }^{6}$, C. Mark Eakin ${ }^{3}$, James P. Gilmour ${ }^{9}$, Nicholas A.J. Graham $^{1,10}$, Hugo Harrison ${ }^{1}$, Jean-Paul A. Hobbs ${ }^{11}$, Andrew Hoey ${ }^{1}$, Mia Hoogenboom ${ }^{1,2}$, Ryan J. Lowe ${ }^{12}$, Malcolm T. McCulloch ${ }^{12}$, John M. Pandolfi ${ }^{13}$, Morgan Pratchett ${ }^{1}$, Verena Schoepf $^{12}$, Gergely Torda ${ }^{1,5}$, Shaun K. Wilson ${ }^{14}$

${ }^{1}$ Australian Research Council (ARC) Centre of Excellence for Coral Reef Studies, James Cook University, Townsville, QLD 4811, Australia

${ }^{2}$ College of Marine \& Environmental Sciences, James Cook University, Townsville, Queensland 4811, Australia

${ }^{3}$ Coral Reef Watch, U.S. National Oceanic and Atmospheric Administration, College Park, MD 20740, USA

${ }^{4}$ Marine Geophysical Laboratory, Physics Department, College of Science, Technology and Engineering, James Cook University, Townsville, QLD 4811, Australia

${ }^{5}$ Australian Institute of Marine Science, PMB 3, Townsville, Queensland 4810, Australia ${ }^{6}$ Department of Biology, University of Victoria, British Columbia, V8W 2Y2, Canada 
$25{ }^{7}$ Red Sea Research Centre, King Abdullah University of Science and Technology, Thuwal 26 23599-6900, Saudi Arabia

$27{ }^{8}$ Queensland Museum, 70-102 Flinders St, Townsville, QLD, 4810, Australia

$28{ }^{9}$ Australian Institute of Marine Science, Indian Ocean Marine Science Centre, UWA, WA 29 6009, Australia

${ }^{10}$ Environment Centre, Lancaster University, Lancaster LA1 4YQ, UK

$31{ }^{11}$ Department of Environment and Agriculture, Curtin University, Perth, WA 6845, Australia

${ }^{12}$ ARC Centre of Excellence in Coral Reef Studies, UWA Oceans Institute, and School of

Earth and Environment, University of Western Australia, Western Australia 6009, Australia

${ }^{13}$ ARC Centre of Excellence for Coral Reef Studies, School of Biological Sciences,

University of Queensland, Brisbane, QLD 4072, Australia

${ }^{14}$ Department of Parks and Wildlife, Kensington, Perth, WA 6151, Australia 
Tropical reef systems are transitioning to a new era in which the interval between recurrent bouts of coral bleaching is too short for a full recovery of mature assemblages. We analyzed bleaching records at 100 globally-distributed reef locations over the past four decades, from 1980 to 2016. The median return-time between pairs of severe bleaching events has diminished steadily since 1980, and is now only six years. As global warming has progressed, tropical sea surface temperatures are warmer now during current La Niña conditions than they were in EI Niño events three decades ago. Consequently, as we transition to the Anthropocene, coral bleaching is occurring more frequently in all El Niño Southern Oscillation phases, increasing the likelihood of annual bleaching in coming decades.

The average surface temperature of our planet has risen by close to $1^{\circ} \mathrm{C}$ since the $1880 \mathrm{~s}(1)$, and global temperatures in 2015 and 2016 were the warmest since instrumental records began in the $19^{\text {th }}$ century (2). Recurrent regional-scale $(>1000 \mathrm{~km})$ bleaching and mortality of corals is a modern phenomenon caused by anthropogenic global warming (3-10). Bleaching prior to the 1980s was recorded only at a local scale of a few tens of kilometres, due to small-scale stressors such as freshwater inundation, sedimentation, or by unusually cold or hot weather (3-5). Bleaching occurs when the density of algal symbionts, or zooxanthellae (Symbiodinium spp.), in the tissues of a coral host diminishes due to environmental stress, revealing the underlying white skeleton of the coral (8). Bleached corals are physiologically and nutritionally compromised, and prolonged bleaching over several months leads to high levels of coral mortality $(11,12)$.

Here, we compiled de novo the history of recurrent bleaching from 1980-2016 for 100 globally-distributed coral reef locations in 54 countries, using a standardized protocol to examine patterns in the timing, recurrence and intensity of bleaching episodes, including the latest global bleaching event in 2015-2016 (Supplementary Table S1). Our findings reveal 
that coral reefs have entered the distinctive human-dominated era characterized as the Anthropocene (13-15), in which the frequency and intensity of bleaching events is rapidly approaching unsustainable levels. At the spatial scale we examined (Supplemental Figure X), the number of years between recurrent severe bleaching events has diminished five-fold in the past 3-4 decades, from 25-30 years in the early 1980’s to once every 5.9 years in 2016. Across the 100 locations, we scored 300 bleaching episodes as severe, i.e. affecting more than $30 \%$ of corals at a scale of 10 s to 100 s of kilometres, and a further 312 as moderate $(<30 \%$ of corals bleached). Our analysis indicates that coral reefs have moved from a period prior to 1980 when regional-scale bleaching was exceedingly rare or absent (3-5), to an intermediary phase beginning in the 1980s when global warming increased the thermal stress of strong El Niño events, leading to global bleaching events. Finally, in the past two decades many additional regional-scale bleaching events are occurring outside of El Niño conditions, affecting more and more former spatial refuges and threatening the future viability of coral reefs.

Increasingly, climate-driven bleaching is occurring in all El Niño Southern Oscillation (ENSO) cycles phases, because as global warming progresses, average tropical sea surface temperatures are warmer today under La Niña conditions than they were during El Niño events only three decades ago (Fig. 1). Since 1980, 58\% of severe bleaching events have been recorded during four strong El Niño events (in 1982-1983, 1997-1998, 2009-2010 and 20152016) (Fig. 2A), with the remaining 42\% occurring during hot summers in other ENSO phases. Inevitably, the link between El Niño as the predominant trigger of mass bleaching (3-5) is diminishing as global warming continues (Fig. 1) and as summer temperature thresholds for bleaching are increasingly exceeded throughout all ENSO phases. 
87 The 2015-2016 bleaching event affected 75\% of the globally-distributed locations we examined (Fig. 2A, Fig. 3), and is therefore comparable in scale to the then unprecedented 1997-1998 event, when 74\% of the same 100 locations bleached. In both periods, sea surface temperatures were the warmest on record in all major coral reef regions $(2,16)$. As the geographic footprint of recurrent bleaching spreads, fewer and fewer potential refuges from global warming remain untouched (Fig. 2B), and only six of the 100 locations we examined have escaped severe bleaching so far(Fig. 2B, Supplementary Table S1).

Following the extreme bleaching recorded in 2015-16, the median number of severe bleaching events experienced across our study locations is now three since 1980 (Fig. 2C). Eighty-eight percent of the locations that bleached in 1997-1998 have since bleached severely at least once again. Since 1980, 31\% of reef locations have experienced four or more (up to nine) severe bleaching events (Fig. 2C), as well as many moderate episodes (Supplementary Table S1). Globally, the annual risk of bleaching (both severe and more moderate events) has increased by a rate of approximately 3.9\% per annum (Supplemental Fig. S1), from an expected $8 \%$ of locations in the early 1980 s to $31 \%$ in 2016 . Similarly, the annual risk of severe bleaching has also increased, at a slightly faster rate of $4.3 \%$ per annum, from an expected 4\% of locations in the early 1980’s to 17\% in 2016 (Supplemental Fig. S1). This trend corresponds to a 4.6-fold reduction in estimated return-times of severe events, from once every 27 years in the early 1980s to every 5.9 years in 2016. Thirty-three percent of return-times between recurrent severe bleaching events since 2000 have been just one, two or three years (Fig. 2D).

Our analysis also reveals strong geographic patterns in the timing, severity and return-times of mass bleaching (Fig. 4). The Western Atlantic, which has warmed earlier than elsewhere $(16,17)$, began to experience regular bleaching early, with an average of 4.1 events per location prior to 1998, compared with 0.4 to 1.6 in other regions (Fig. 4, Supplemental Fig. 
112 S1). Furthermore, widespread bleaching (affecting $>50 \%$ of locations) has now occurred seven times since 1980 in the Western Atlantic, compared to three times for both Australasia and the Indian Ocean, and only twice in the Pacific. Over the entire period, the number of bleaching events has been highest in the Western Atlantic, with an average of 10 events per location, 2-3 times more than other regions (Fig. 4).

In the 1980s, bleaching risk was highest in the Western Atlantic, followed by the Pacific, with the Indian Ocean and Australasia having the lowest bleaching risk. However, bleaching risk increased most strongly over time in Australasia and the Middle East, at an intermediate rate in the Pacific, and slowly in the Western Atlantic (Fig. 4, Supplemental Fig. S2B, Supplemental Tables S2 and S3). The return-times between pairs of severe bleaching events is declining in all regions (Supplemental Fig. S2C), with the exception of the Western Atlantic where most locations have escaped a major bleaching event since 2010 (Fig. 2D).

We tested the hypothesis that the number of bleaching events that have occurred so far at each location is positively related to the amount of post-industrial warming of sea surface temperatures that has been experienced there (Supplemental Fig. S3). However, we found no significant relationship for any of the four geographic regions, consistent with each bleaching event being caused by a short-lived episode of extreme heat $(16,18,19)$ that is superimposed on much smaller long-term warming trends. Hence, the long-term predictions of future average warming of sea surface temperatures (17) are also unlikely to provide an accurate projection of bleaching risk or the location of spatial refuges over the next century.

In coming years and decades, climate change will inevitably continue to increase the number of extreme heating events on coral reefs, and further drive down the return-times between them. Our analysis indicates that we are already approaching a scenario where every hot summer, with or without an El Niño event, has the potential to cause bleaching and mortality 
at a regional scale. The time between recurrent events is increasingly too short to allow a full

137 recovery of mature coral assemblages, which generally takes 10-15 years for the fastest

138 growing species and far longer for the full complement of life histories and morphologies of

139 older assemblages (20-23). Areas that have so far escaped severe bleaching are likely to

140 decline further in number (Fig. 2B), and the size of spatial refuges will diminish. These

141 impacts are already underway with slightly less than $1^{\circ} \mathrm{C}$ of global average warming. Hence,

$1421.5^{\circ} \mathrm{C}$ or $2^{\circ} \mathrm{C}$ of warming above pre-industrial conditions will inevitably contribute to further

143 degradation of the world's coral reefs (18). The future condition of reefs, and the ecosystem

144 services they provide to people, will depend critically on the trajectory of global emissions

145 and on our diminishing capacity to build resilience to recurrent high-frequency bleaching

146 through management of local stressors (15), before the next bleaching event occurs. 


\section{REFERENCES AND NOTES}

1. D. L. Hartmann et al., in Climate Change 2013: The Physical Science Basis. Contribution of Working Group I to the Fifth Assessment Report of the Intergovernmental Panel on Climate Change, T. F. Stocker, Ed. (Cambridge University Press, 2013).

2. National Aeronautics and Space Administration (NASA). Global Analysis - 2016 year-to-date temperatures versus previous years (2016) https://www.ncdc.noaa.gov/sotc/global/2016/10/supplemental/page-2

3. P.W. Glynn, Coral reef bleaching: ecological perspectives. Coral Reefs 12, 1-17 (1993).

4. G. M. Wellington, P. W. Glynn, in Geological Approaches to Coral Reef Ecology, R. B. Aronson, Ed. (Springer, Berlin, 2007).

5. J. K. Oliver, R. Berkelmans, C. M. Eakin, in Ecological Studies: Analysis and Synthesis, M. J. H. van Oppen, J. M. Lough, Eds. (2009).

6. J. A. Kleypas, G. Danabasoglu, J. M. Lough, Potential role of the ocean thermostat in determining regional differences in coral bleaching events. Geophys. Res. Lett. 35, L03613, (2008), doi:10.1029/2007GL032257.

7. S. D. Donner, G. J. M. Rickbeil, S. F. Heron, A new high-resolution global mass coral bleaching database. PLoS ONE 12, e0175490, (2017). doi.org/10.1371/journal.pone.0175490.

8. A. C. Baker, P. W. Glynn, B. Riegl, Climate change and coral reef bleaching: An ecological assessment of long-term impacts, recovery trends and future outlook. Estuar. Coast. Shelf Sci. 80, 435-471 (2008).

9. T. P. Hughes, et al., Climate change, human impacts, and the resilience of coral reefs. 
Science 301, 929-933 (2003).

10. J. E. Carilli, R. D. Norris, B. Black, S. M. Walsh, M. McField, Century-scale records of coral growth rates indicate that local stressors reduce coral thermal tolerance threshold. Glob. Chang. Biol. 16, 1247-1257 (2010).

11. A. H. Baird, P. A. Marshall, Mortality, growth and reproduction in scleractinian corals following bleaching on the Great Barrier Reef. Mar. Ecol. Prog. Ser. 237, 133$141(2002)$.

12. M. D. Spalding, B. E. Brown, Warm-water coral reefs and climate change. Science, 350, 769-771 (2015).

13. P. J. Crutzen, in Earth System Science in the Anthropocene, E. Ehlers, T. Krafft, Eds. (Springer, 2006).

14. J. Rockström et al., A safe operating space for humanity. Nature 461, 472-475 (2009).

15. T. P. Hughes et al., Coral reefs in the Anthropocene. Nature 543, 36-44 (2017).

16. J. M, Lough, 1997-98: Unprecedented thermal stress to coral reefs? Geophys. Res. Lett. 27, 3901-3904 (2000).

17. O. Hoegh-Guldberg et al., in Climate Change 2014: Impacts, Adaptation and Vulnerability. Part B: Regional Aspects: Contribution of working group II to the Fifth Assessment Report of the Intergovernmental Panel on Climate Change, T. F. Stocker, Ed. (Cambridge University Press, 2013).

18. S. F. Heron, J.A. Maynard, R. van Hooidonk, C.M. Eakin, Warming trends and bleaching stress of the world's coral reefs 1864-2012. Sci. Rep. 6, 38402 (2016).

19. T. P. Hughes et al., Global warming and recurrent mass bleaching of corals. Nature 543, 373-377 (2017). 
20. H. Kayanne, S. Harii, Y. Ide, F. Akimoto, Recovery of coral populations after the 1998 bleaching on Shiraho Reef, in the southern Ryukyus, NW Pacific. Mar. Ecol. Prog. Ser. 239, 93-103 (2002).

21. J. P. Gilmour, L. D. Smith, A. J. Heyward, A. H. Baird, M. S. Pratchett, Recovery of an isolated coral reef system following severe disturbance. Science 340, 69-71 (2013).

22. P.W. Glynn et al., Coral recovery in the Galapagos Islands: the northernmost islands (Darwin and Wenman). Coral Reefs 34, 421-436 (2015).

23. T. R. McClanahan, Decadal coral community reassembly on an African fringing reef. Coral Reefs 33, 939-950 (2014).

24. N. A. Rayner et al., 2003 Global analyses of sea surface temperature, sea ice, and night marine air temperature since the late nineteenth century. J. Geophys. Res. 108, 4407, (2003), doi:10.1029/2002JD002670.

25. W. N. Venables, B. D. Ripley, (2002) Modern Applied Statistics with S (Springer, New York, ed. 4, 2002)

26. D. Bates, M. Maechler, B. Bolker, S. Walker, Fitting Linear Mixed-Effects Models Using lme4. J. Stat. Soft. 67, 1-48, (2015), doi:10.18637/jss.v067.i01.

27. M. D. Spalding, C. Ravilious, E. P. Green (2001) World Atlas of Coral Reefs (UNEPWCMC, Cambridge, 2001)

\section{ACKNOWLEDGEMENTS}

Major funding for this research was provided by the Australian Research Council's Centre of Excellence Program (CE140100020) and an Australian Laureate Fellowships to TPH (FL120100063). The contents of this manuscript are solely the opinions of the authors and do not constitute a statement of policy, decision or position on behalf of NOAA or the U.S.

Government. Data reported in this paper are tabulated in the Supplementary Materials. 
MOVE TO SM: Although several global databases of bleaching records are available

220 (notably ReefBase, reefbase.org), they suffer from intermittent or lapsed maintenance, and

221 from uneven sampling effort across both years and locations (7). The time-spans of five

222 earlier global studies of coral bleaching range from 1870-1990 (3), 1960-2002 (4), 1973-2006

223 (5), 1980-2005 (6), and 1985-2010 (7). None of these studies accounted fully for the scale of

224 bleaching observations, or for bias in the locations and timing of bleaching records.

225 For example, following bleaching along the Great Barrier Reef in 1998, 2002 and 2016, 29\%

226 of individual reefs have bleached three times, and only 9\% remain unaffected (25).

227

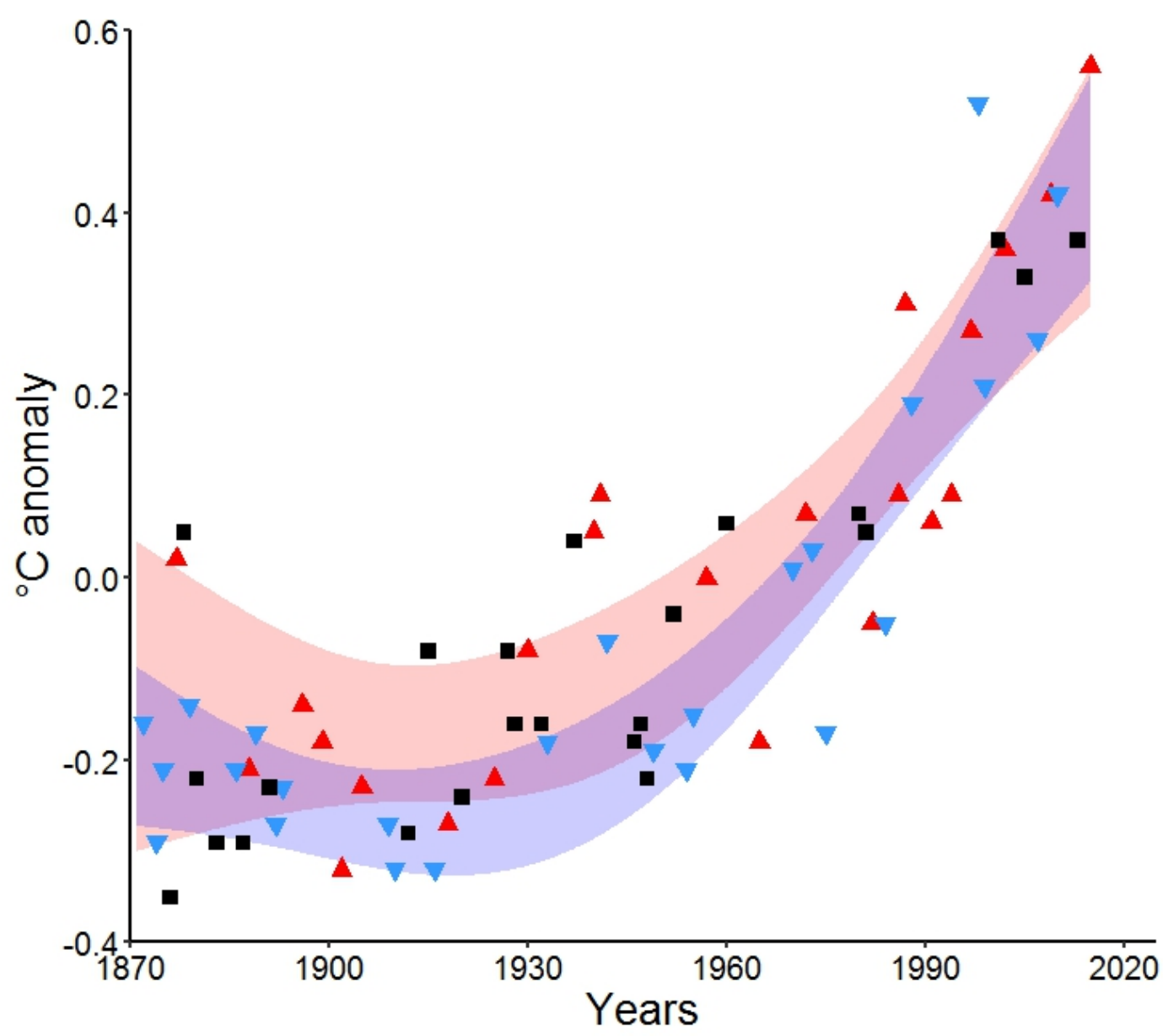


231 Fig. 1. Global warming throughout ENSO cycles. Sea surface temperature anomalies from 232 1871-2016, relative to a 1961-1990 baseline, averaged across 1,670 1-degree latitude by 233 longitude boxes containing coral reefs between latitudes of $31^{\circ} \mathrm{N}$ and $31^{\circ} \mathrm{S}$.. Data points 234 differentiate El Niño (red triangles), La Niña (blue triangles) and El Niño Southern

235 Oscillation neutral periods (black squares). Ninety-five percent confidence intervals are 236 shown for non-linear regression fits for years with El Niño and La Niña conditions (red and 237 blue shading, respectively). 

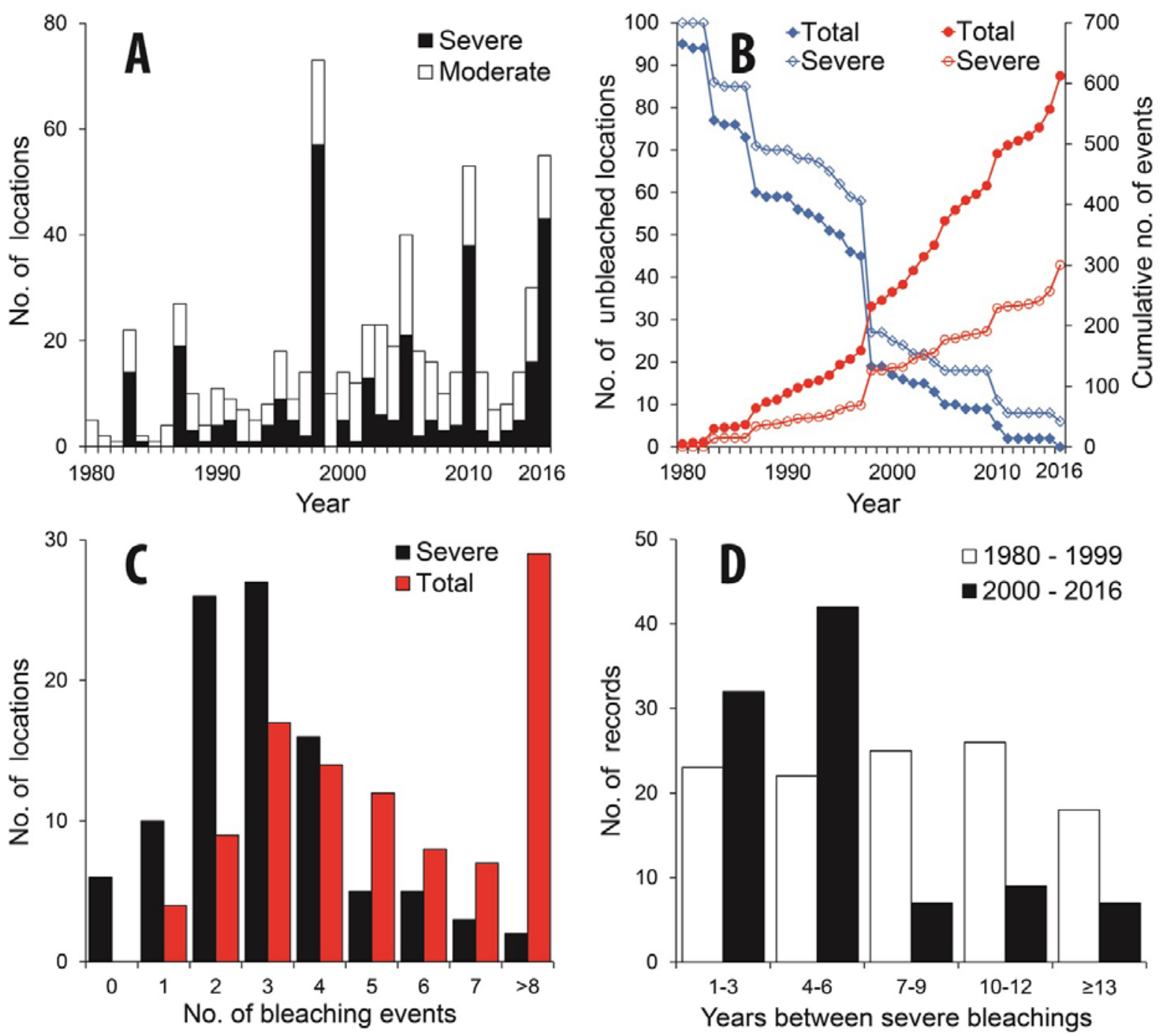

Fig. 2. Temporal patterns of recurrent coral bleaching. (A) Number of 100 pan-tropical locations that have bleached each year from 1980 to 2016. Black bars indicate severe bleaching affecting $>30 \%$ of corals, and white bars depict moderate bleaching of $<30 \%$ of corals. (B) Cumulative number of severe and total bleaching events since 1980 (red; right axis), and depletion of locations through time that remain free of any or severe bleaching

247 (blue; left axis). (C) Frequency-distribution of number of severe (black) and total bleaching events (red) per location. (D) Frequency distribution of return-times (number of years) between successive severe bleaching events from 1980-1999 (white bars) and 2000-2016 (black bars). 
251

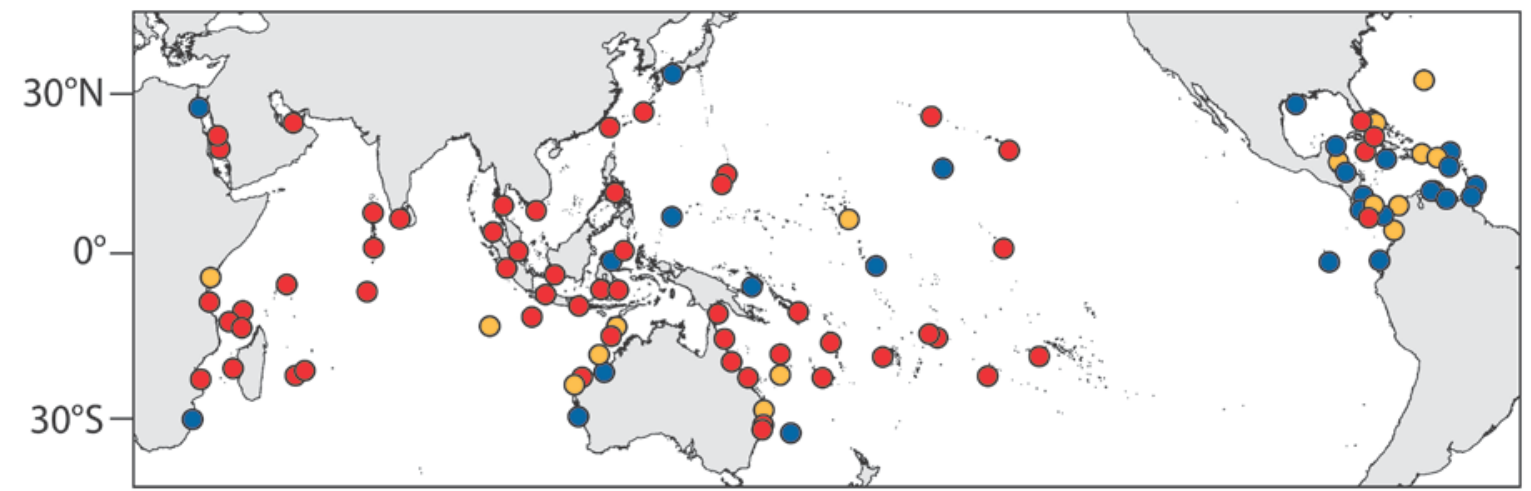

252 Fig. 3. The global extent of mass-bleaching of corals in 2015-2016. Symbols show 100 reef locations that were assessed: red - severe bleaching affecting $>30 \%$ of corals; orange -

254 moderate bleaching affecting $<30 \%$ of corals; blue circles - no significant bleaching 255 recorded. See Supplemental Table 1 for further details. 

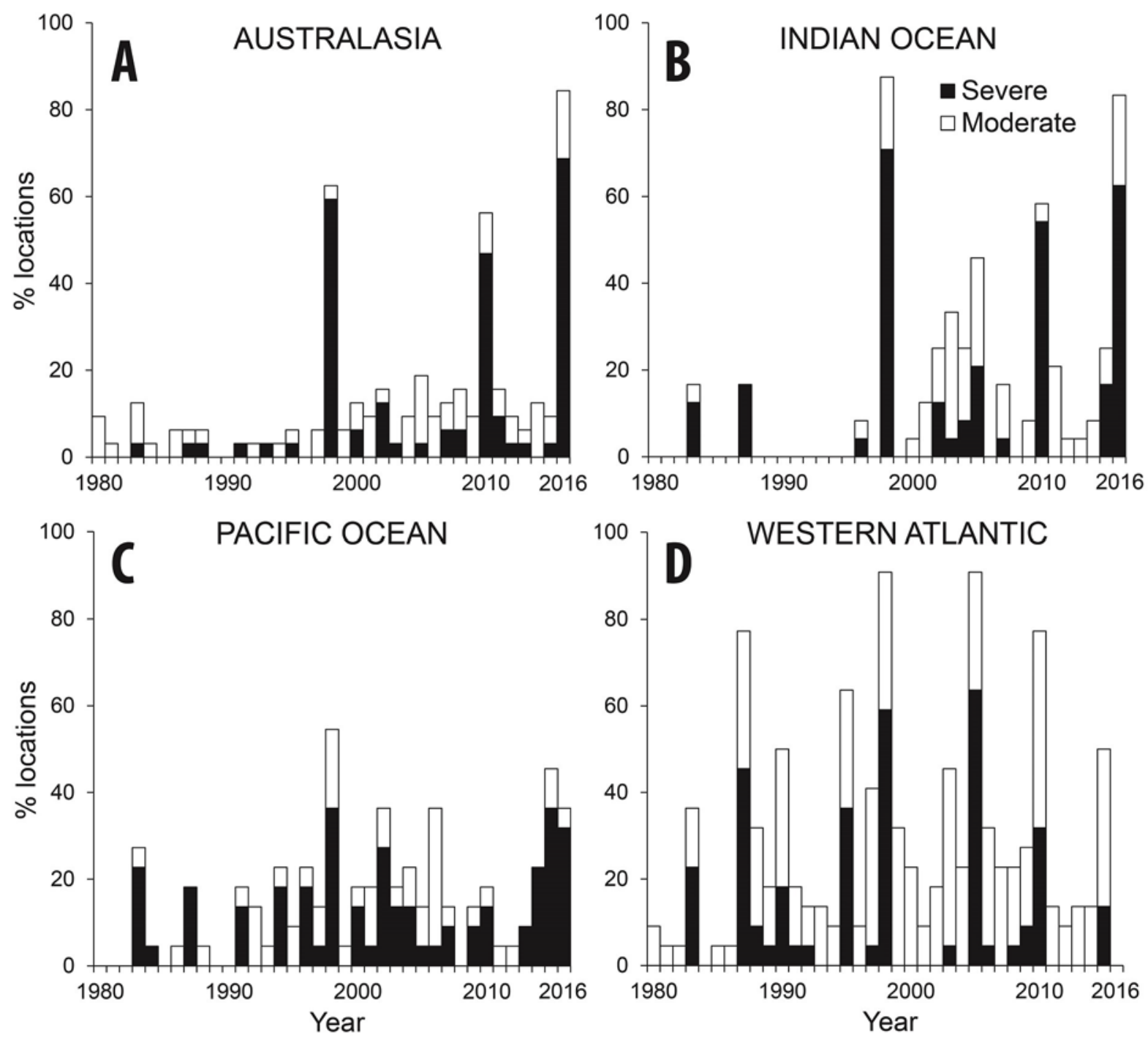

258 Fig. 4. Geographic variation in the timing and intensity of coral bleaching, from 1980-

2016. (A) Australasia (32 locations). (B) Indian Ocean (24 locations). (C) Pacific Ocean (22

260 locations). (D) The Western Atlantic (22 locations). For each region, black bars indicate the

261 percentage of locations that experienced severe bleaching, affecting $>30 \%$ of corals. White

262 bars indicate the percentage of locations per region with additional moderate bleaching

263 affecting $<30 \%$ of corals. 